\title{
Construction Cost-Based Effectiveness Analysis of Green and Grey Infrastructure in Controlling Flood Inundation: A Case Study
}

\author{
Jiada Li, ${ }^{1}$ Tao Tao, ${ }^{2}$ Mason Kreidler, ${ }^{1}$ Steven Burian ${ }^{1}$ and Hexiang Yan $^{2}$ \\ ${ }^{1}$ University of Utah, Salt Lake City, Utah; ${ }^{2}$ Tongji University, Shanghai City, China.
}

\begin{abstract}
Global climate change and rapid urbanization have increased the frequency of urban flooding. In this work, SWMM was used to simulate the implementation of low impact development (LID) practices, drainage network reconstruction, and detention tanks to evaluate potential reductions in flood severity in the TQ subdistrict of SH city, China. Two assessment indexes, construction costs and construction effectiveness, were used to evaluate model results for three scenarios. Construction effectiveness was quantified by reductions in total flood volume and peak flow rate. Results show that LID practices such as permeable pavement and sunken green space mitigate the flooding by reducing total flood volume by $8.6 \%$ and decreasing surface runoff by $7.9 \%$, at a cost of $\$ 0.34$ million. Reconstructing the drainage network reduced total flood volume by $38.4 \%$, which is less than the $46.6 \%$ given by detention storage construction. However, the peak flow for drainage network reconstruction decreased by $46.6 \%$ and peak flow for detention construction was reduced by $50.1 \%$. Despite the lower peak flows, three nodes experienced flood durations longer than the general guideline of $1 \mathrm{~h}$ for network reconstruction, while only two nodes did so with detention tanks. Thus, detention tanks are more effective in reducing the effects of flooding than drainage network reconstruction. Detention tanks are also more cost effective, costing $\$ 1.59$ million, while network reconstruction cost $\$ 1.74$ million. While this study considers flood risk reduc-tion only in regard to economics and effectiveness, the benefits extend to the environment, ecology and human populations. Consequently, this paper can be used as a guide for planners and engineers who make flood mitigation decisions in using these techniques for balancing construction costs and effectiveness. This study should be meaningful for urban stormwater system design, planning, and construction in other southeastern cities of China with high water coverage ratios.
\end{abstract}

\section{Introduction}

The probability of extreme rainfall in cities has increased considerably due to the influence of global climate change and increased urbanization which cause heat island and rain island effects. Flooding in urban areas is consequently becoming more serious (Gilroy and McCuen 2012). The overall trend in the numbers of flood events and torrential rain disasters has fluctuated but it rose from 2005 to 2015 (IPCC 2014). Recently, however, flood events have increased drastically in number and impact. There were 171 flood events across the globe from 2005 to 2014, resulting in 5938 deaths, but there were 152 flood disasters in 2015 alone, resulting in 3310 deaths worldwide (UNISDR 2015; Butler and Davies 2000). Urban flooding tends to occur where stormwater exceeds the urban drainage capacity (Cizek et al. 2017; Hammond et al. 2015). Thus, there is a need to increase urban drainage system conveyance and storage capacity in order to reduce the flooding risks in more frequent extreme weather events due to global climate change (Chen et al. 2014; Liu et al. 2014).

In the past, the first choice for planners wanting to increase drainage capacity had been to upgrade the drainage network or replace existing pipes (Waters 2003). While this approach may prevent flooding, it is not necessarily the most cost effective, resilient or sustainable solution. Low impact development (LID), which includes techniques such as green roofs, permeable pavements, sunken green spaces, swales and bioretention tanks, has become more widely accepted in urban areas by engineers and researchers (Hu et al. 2017). LID design aims to control stormwater by using green infrastructure for water absorption, storage, seepage, purification and drainage when a rain event occurs (Ahiablame et al. 2012). LID has been frequently studied by scholars and used by engineers because it is efficient in terms of perviousness, retention, infiltration and reuse of stormwater (Liu et al. 2015; Liu et al. 2016; Sun et al. 2016; Zhuoxi et al. 2012). Thus LID is a sensitive and sustainable approach to managing urban

Li, Jiada, Tao Tao, Mason Kreidler, Steven Burian and Hexiang Yan. Construction Cost-Based Effectiveness Analysis of Green and Grey Infrastructure in Controlling Flood Inundation: A Case Study. Journal of Water Management Modeling 27: C466. doi: 10.14796/JWMM.C466.

(c) CHI 2019. www.chijournal.org ISSN 2292-6062. 
flooding (Andoh et al. 1997; Palhegyi 2009; Qin et al. 2013; Damodaram et al. 2012).

However, Schneider and McCuen (2006) found that LID may only control stormwater for small storms, and is therefore not as effective as conventional detention storage in controlling flood events (Damodaram et al. 2010). Thus LID is unlikely to solve flooding problems without complementary measures. To address these shortcomings, Damodaram et al. (2010) and Qin et al. (2013) suggested innovative strategies for combining LID techniques with conventional drainage capacity upgrades to control runoff from storm events. Although LID and conventional techniques have been widely studied for the reduction of runoff, peak flow and total flood volume, there have been few studies of the performance of combined LID and conventional techniques in reducing urban flooding. Likewise, there have been few studies that verify the cost and effectiveness of LID technologies. Liu et al. (2015) and Liu et al. (2016) found that for initial expenditure on LID, the environmental benefits increase rapidly as expenditure increases. There have been some cost analyses but much work still needs to be done to identify all the costs. Few researchers have attempted to simulate and analyze the cost effectiveness of LID construction under various rainfall characteristic scenarios such as total volume, rainfall duration and rainfall intensity, especially including preliminary precipitation, mainly from the beginning of storms, which might have significant effects on flood risk management of drainage networks.

We selected a subdistrict of SH city, TQ, that is particularly suitable for LID installation, and we used the Storm Water Management Model, SWMM (Rossman 2010) to quantify the effects of combining LID, network reconstruction and detention storage construction. The workflow was as follows. We acquired drainage network information, DEM data, and other necessary current data from the SH Municipal Engineering Design Institute to build a drainage network model of TQ. The SWMM model was then used to simulate the flooding of urban areas. To better visualize the baseline flooding under a 20 y storm, two-dimensional InfoWorks ICM software was also used to map the initial flooding locations (Rhodes and Fice 2014). In view of the current flooding situation in TQ, the LID technology, construction of detention tanks and reconstruction of the drainage network were each modeled to solve the problem of flooding in TQ. Finally, the effects of these three technologies on the reduction of urban flooding was evaluated by calculating the cost effectiveness of the reductions in total flow volumes and peak flow rates.

\section{Methods}

\subsection{Study Area}

\section{Area Overview}

The TQ subdistrict is located in SH city, surrounded by PD South Road, the Inner Ring Elevated Road, DF Road and the ZJ River. TQ was chosen as the study area for the following four reasons:
. the high amount of green land, $18.1 \%$ in this area, makes it more suitable for LID construction;

- the low standard and outdated drainage networks do not reduce flooding when extreme rain events occur;

- increased development has negatively affected this area by causing waterlogging in some areas; and

- this area has a $9.8 \%$ water cover ratio and it is close to the YP river with an isolated border line, making this area more visible than other areas, and therefore preferable for the introduction of green technology.

The total area of TQ is $3.86 \mathrm{~km}^{2}$. The residential district accounts for $39.1 \%$ and public infrastructure occupies $42.6 \%$ of the whole area (Quan et al. 2010).

\section{Precipitation Information for TQ}

Precipitation data for TQ is archived in the Pudong Drainage Management Administration. The rainfall time series data were collected from 2011-05-01 to 2011-09-30 by a rain gauge installed at the pump station. We filtered the rainfall data to exclude events $\leq 5 \mathrm{~mm}$ to analyze rainfall frequency, duration and intensity, which can be combined using the Huff method to define the principal rainfall intervals. Consequently, single rainfall events were separated by intermediate periods defined as precipitation $<0.5 \mathrm{~mm}$ or no rain event for $<12 \mathrm{~h}$. The precipitation data statistics show that rainfall in TQ ranged from $5.9 \mathrm{~mm}$ to $59.9 \mathrm{~mm}$ during the study period with 5 events defined as light, 11 events defined as moderate and 8 events defined as heavy, in addition to 1 rainstorm. The average precipitation was $21.7 \mathrm{~mm}$, generally occurring in long duration events. Rainfall intensity was $0.02 \mathrm{~mm} /$ $\mathrm{min}-0.04 \mathrm{~mm} / \mathrm{min}$ and most rain falls in June. Chukwuma and Schwab (1983) defined the preliminary, medium and terminal stages of one rainfall event by breaking down the rainfall period into $0 \mathrm{~h}-12 \mathrm{~h}, 12 \mathrm{~h}-24 \mathrm{~h}$ and $24 \mathrm{~h}-72 \mathrm{~h}$. The proportion of rainfall stages according to this definition is shown in Figure 1. From Figure 1, it can be seen that most intense single rain events (51\%) occur in the preliminary stage. We concluded that most precipitation in TQ is during the preliminary period of rainfall.
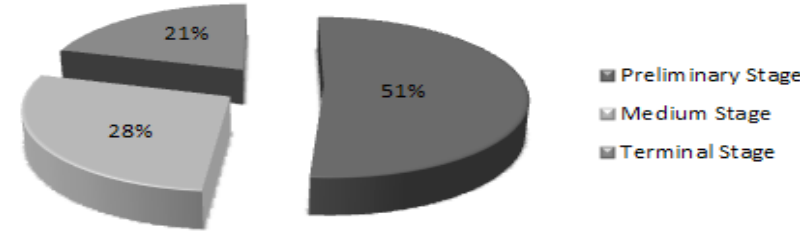

Figure 1 Different rainfall stages.

\subsection{Model Setup}

\section{Hydrologic Modeling}

In this study, the duration of rainfall modeling was $120 \mathrm{~min}$. The interval of rainfall modeling was 5 minutes and the return periods of rainfall modeling were $3 y, 5 y, 10 y$ and $20 y$ to create the 
precipitation time series as the rainfall pattern input in modeling. The $3 y, 5 y, 10 y$ and $20 y$ rainfall scenarios can be seen in Figures 2 and 3.

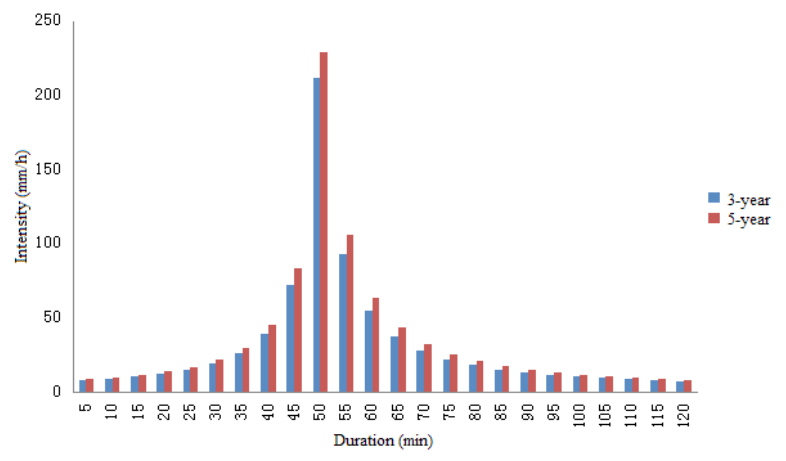

Figure 2 Rainfall patterns (3 y, 5 y) with 120 min duration.

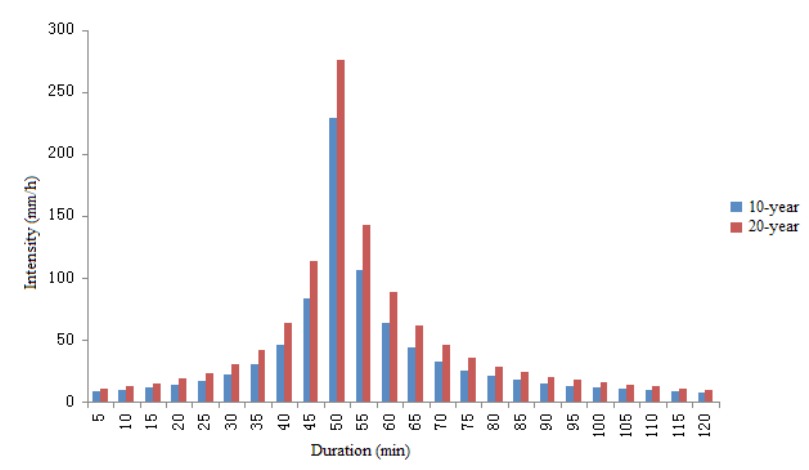

Figure 3 Rainfall patterns (10 y, $20 \mathrm{y})$ with 120 min duration.

\section{Drainage Network Modeling}

Based on the field data for TQ, the drainage network model was constructed in SWMM as shown in Figure 4. We used SWMM 5.1 to simulate the effects of LID technology, drainage network reconstruction and detention tanks in handling urban flooding in TQ. The field and modeling elements of this network are summarized in Table 1.

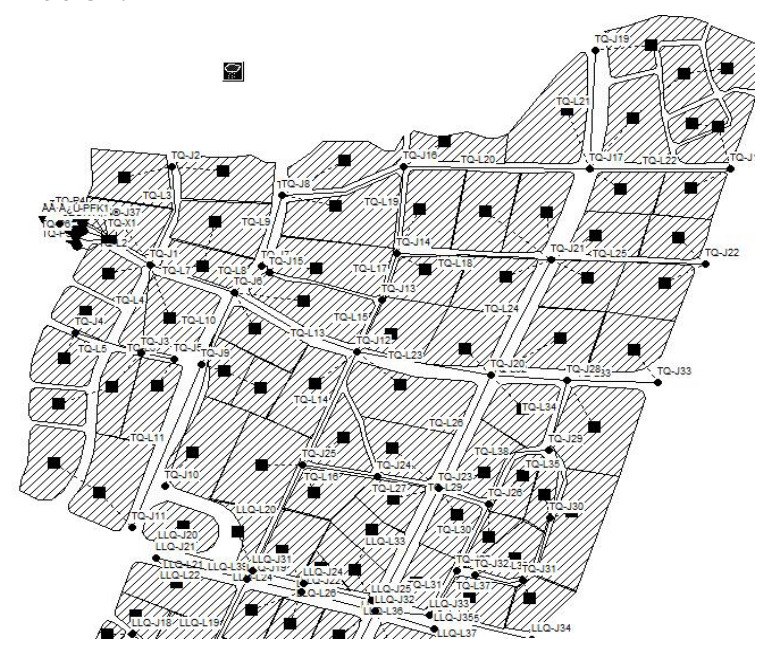

Figure 4 SWMM model of TQ drainage network.
Table 1 Summary of the elements of the T0-Q drainage system.

\begin{tabular}{llcl}
\hline \multicolumn{1}{c}{ Modeling } & \multicolumn{1}{c}{ Elements } & Number & \multicolumn{1}{c}{ Parameters and value } \\
\hline Subcatchment & Drainage area & 48 & Area: $1.41 \mathrm{~m} \times 104 \mathrm{~m}-7.19 \mathrm{~m} \times 104 \mathrm{~m}$; \\
& & & Total: $199.25 \mathrm{~m} \times 104 \mathrm{~m}$ \\
Node & Inspection well & 37 & Depth: $2.24 \mathrm{~m}-6.5 \mathrm{~m}$; Average: $3.31 \mathrm{~m}$ \\
Connection & Drainage pipe & 37 & Diameter: DN450 mm-2400 mm; Total $12650 \mathrm{~m}$ \\
Water storage & Pump & 1 & Length $\times$ Width $\times$ Height: $24 \mathrm{~m} \times 6.5 \mathrm{~m} \times 9 \mathrm{~m}$ \\
\hline
\end{tabular}

The $3 \mathrm{y}$ and $5 \mathrm{y}$ rainfalls with 120 min duration were chosen as the rainfall model input. With these inputs, those nodes having a flooding time within $1 \mathrm{~h}$ of the status reporter in SWMM were considered as the nonwaterlogging points (Elliott and Trowsdale 2007). However, when the $10 \mathrm{y}$ and $20 \mathrm{y}$ rainfalls with $120 \mathrm{~min}$ duration were used as input for the rainfall model, the drainage network in TQ suffered many $>1 \mathrm{~h}$ waterlogged nodes, indicating possible heavy flooding.

Prior to SWMM modeling, two-dimensional InfoWorks ICM software was used to map the initial flooding conditions and submerged locations, shown in Figure 5. Yellow areas are those with the heaviest flooding, the dark blue nodes are second heaviest and the light blue areas are the least severe. The areas experiencing the heaviest flooding are those identified as areas 1, 2, 3 and 4 in Figure 5. The greatest flooding resulted from sewer overflows, and these areas should be considered for implementation of LID technology, such as permeable pavement, sunken green space, detention tanks and reconstruction of the drainage network.

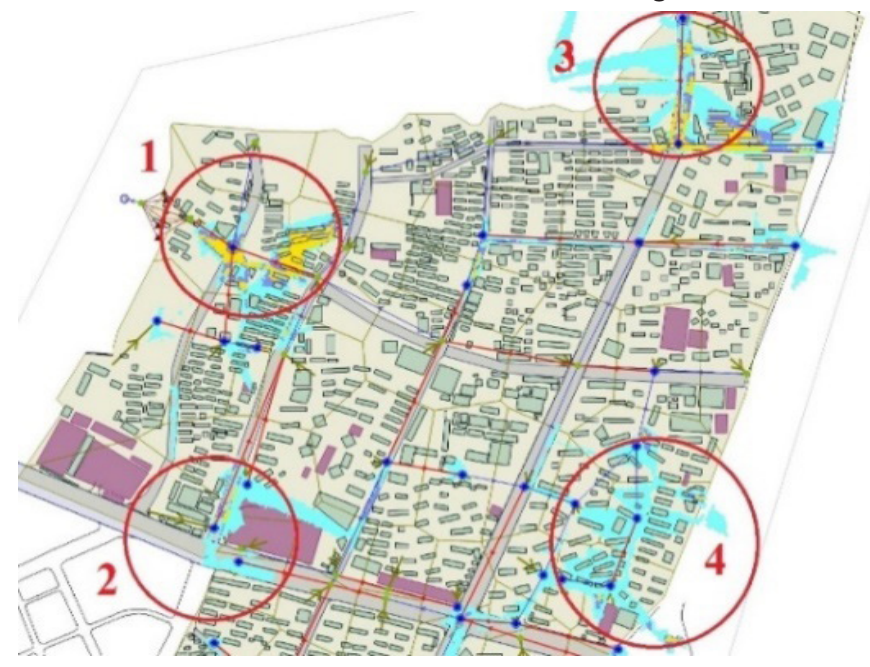

Figure 5 Modeling results for $20 \mathrm{y}$ rainfall.

\subsection{Implementing Flood Reduction Technologies}

To significantly reduce flooding risk and provide ecological benefits, green and grey infrastructure should work together to alleviate flood severity. We used the SWMM model to simulate flood reduction from permeable pavement, sunken green space, detention tanks and drainage network reconstruction. These four technologies were selected for the following reasons: 
1. There are two parks with soft mud and large amounts of land in TQ which make it easier to construct detention tanks and sunken green space and also to reduce construction costs.

2. The high water and green coverage ratios ( $9.8 \%$ and $18.1 \%$ ) in TQ make it more efficient to connect the permeable pavement to water filtration and water storage equipment.

3. There are green plants around permeable pavement in the TQ area, making the technology more effective.

4. Compared with other LID technologies, permeable pavement and sunken green space are more cost effective since they reduce pollutant loads and runoff from preliminary rainfall periods that are common in TQ.

5. LID practices reduce the impact of urbanization on the environment.

6. Construction of detention tanks and network reconstruction are suitable ways to reduce flooding.

\section{Permeable Pavement Design}

We used permeable pavement and sunken green space as the main LID measures to control rainwater in this area. Based on the manual calculation, permeable pavement in area 1 is simulated as $1100 \mathrm{~m}$ long and $1.5 \mathrm{~m}$ wide, while the pavement in area 3 is $930 \mathrm{~m}$ long and $1.5 \mathrm{~m}$ wide. In total, the area of simulated permeable pavements is $3045 \mathrm{~m}^{2}$, which is $0.078 \%$ of the total area of TQ. The effects of increasing the LID ratio from $0.078 \%$ to $1 \%$ were modeled, which indicated that increasing the LID ratio not only increases the construction costs but also reduces the space available for other flood mitigation techniques as the underlying coarse aggregate layer increases. We therefore assumed that $0.078 \%$ was the best area ratio of LID practice.

Permeable paving includes a range of sustainable materials and techniques for permeable pavements with a base and subbase that permit the movement of storm water from the surface. We simulated the transformation of pavements in areas 1 and 3 into permeable pavement (see Figure 5 above). The thickness of the pavement structure was calculated using Equation 1 (Pan et al. 2000):

$$
H=(0.1 i-3600 q) t / 60 v
$$

where:

$$
\begin{aligned}
H= & \text { thickness of the permeable pavement structure, } \\
& \mathrm{cm}, \\
i= & \text { rainfall intensity, } \mathrm{mm} / \mathrm{h}, \\
q= & \text { average permeability coefficient of the soil, } \mathrm{cm} / \mathrm{s}, \\
t= & \text { rainfall duration, min, and } \\
v= & \text { average effective porosity of permeable } \\
& \text { pavement layer, \%. }
\end{aligned}
$$

At the time of writing there are no national permeable pavement design standards in China, so permeable pavements were designed to meet the minimum requirement that runoff will not occur after 60 min of a 2 y storm rainfall, as specified in technical guidelines provide by the Stormwater Utilization Technical Guidelines of Beijing in Zhang et al. (2012). This rainfall intensity was calculated according to the newly added formula for $\mathrm{SH}$ rainfall intensity in Gironás et al. (2009). To enable the permeable pavement to have a certain infiltration ability, $q$ (the average permeability coefficient of the soil) should be $>0.004 \mathrm{~mm} / \mathrm{s}$ and $v$ (the average effective porosity of the permeable pavement layer) should be $\geq 15 \%$ of the infiltration rate. Finally, it was calculated that the permeable pavement brick thickness was $30 \mathrm{~mm}$ $40 \mathrm{~mm}$. The thickness of the underlying surface was $0.3 \mathrm{~m}-0.5 \mathrm{~m}$. In this way, infiltration velocity was calculated as $0.75 \mathrm{~mm} / \mathrm{s}$ with a $15.5 \%$ infiltration rate.

\section{Sunken Green Space Technology}

Area 2 was converted from park land to sunken green space. Although the park area was already at a lower elevation than the surrounding highway, the higher elevation along the edge of the park prevents runoff from accumulating there. To mitigate this, we simulated small drainage channels beside the road to allow runoff to pond in the park. Area 4 is part of a residential area, in which green coverage is high and distributed relatively evenly. It can be transformed into a sunken green space to induce rainwater infiltration and detention in order to reduce flow in the drainage system. Geologic parameters were not available for the study area, however, making it difficult to create a calculation curve for the sunken green space. As a result, the calculation curves for HD city, shown in Figure 6, were used instead.

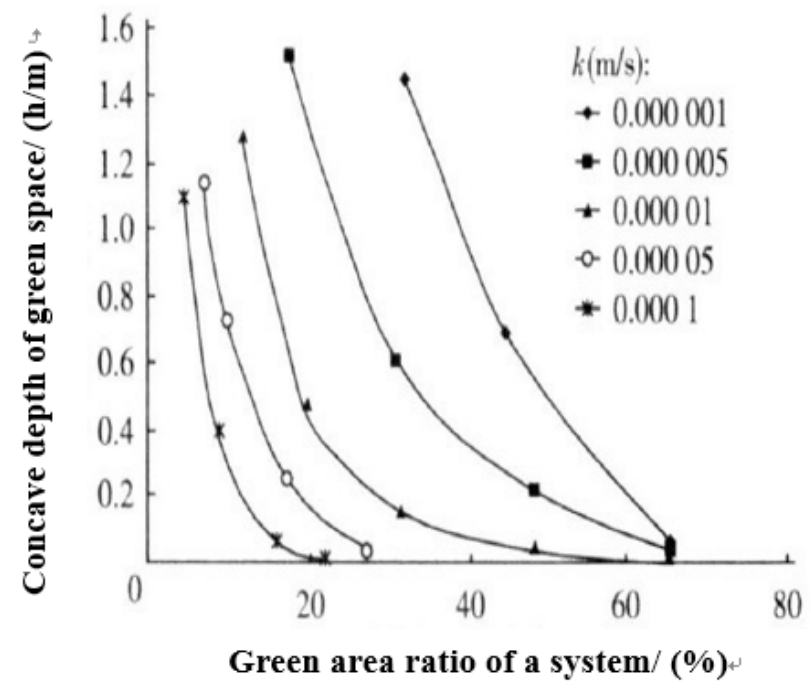

Figure 6 Permeability coefficient calculation curves for sunken green space in HD.

The average permeability coefficient of grassland soil in $\mathrm{SH}$ city was $5.35 \times 10^{-6} \mathrm{~m} / \mathrm{s}$, the same as the hydraulic conductivity; the permeability coefficient was taken to be $5 \times 10^{-6} \mathrm{~m} / \mathrm{s}$, which is typical for grassland soil in SH city (Hu et al. 2003). The design return period for the sunken green space was $2 \mathrm{y}$. In the SWMM drainage network model of area 4, the study region was divided 
into 12 subcatchments. For six subcatchments the permeability areas were too small to transform; for the remaining subcatchments the permeability area ratios were about $30 \%$, so the sunken depth of these areas was taken as $0.6 \mathrm{~m}$. However, given that the groundwater level in $\mathrm{SH}$ city is higher than in $\mathrm{HD}$, mostly in the range $0.5 \mathrm{~m}-1.5 \mathrm{~m}$ (Wei et al. 2010), the final sunken depth was designed to be $0.45 \mathrm{~m}$. Transformation of green space occurred mainly in area 4. The SWMM model calculated the total transformed catchments of area 4 to be $78100 \mathrm{~m}^{2}$, which is $2 \%$ of the total catchment area.

\section{Drainage Network Reconstruction}

Drainage network reconstruction was planned according to analysis of the specific pipelines in each flooded area, using metrics such as pipe diameter, flow direction and whether the pipeline had adverse slope, by means of adding pumps and pipelines and increasing pipe diameters. The causes of urban flooding were determined from the specific circumstances to decide the appropriate reconstruction technology.

To improve the flooding situation, a model of the drainage system of TQ was built to simulate the ability of the system to control runoff. In the SWMM model, overload occurs when the water level exceeds the highest node elevation of the pipes. If the overflow occurs at the node, it is called node flooding. Drainage system pipes will experience overload if the system is at full flow. In order to test the capacity of the drainage system most thoroughly, a 120 min rainfall of a 20 y storm was input. There are some misconnections between pipelines and some node flooding occurs in the drainage system which was given in the summary of node flooding in the SWMM run status report. If a node is flooded for $>1 \mathrm{~h}$, then the risk of flooding becomes greater. Four areas $>1 \mathrm{~h}$ flooding were chosen as the research objects.

The basic method was to optimize the length and diameter of pipes until overloading was $<1 \mathrm{~h}$, depending on the specific circumstances of each area (Figure 7). The corresponding reconstruction approaches were determined as described below.

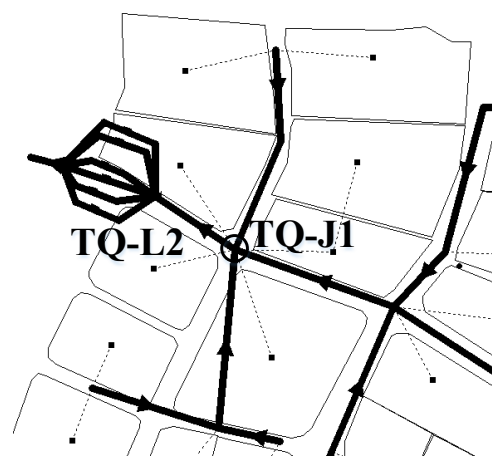

(a)

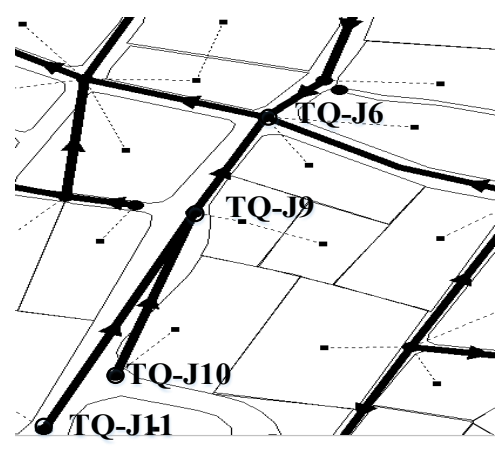

(b)

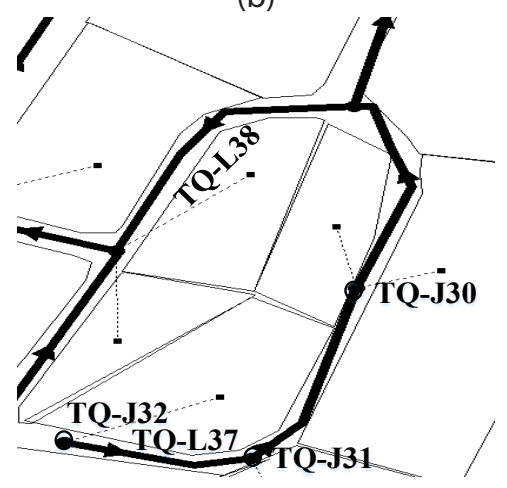

(c)

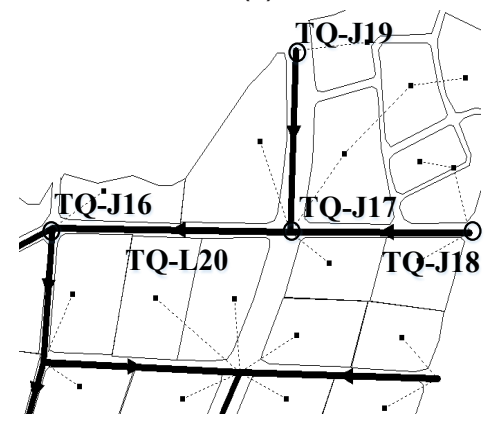

(d)

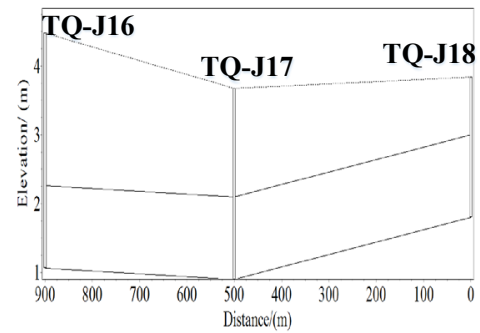

(e)

Figure 7 SWMM model of seriously flooded areas in TQ subdistrict (a: area 1 flooding; b: area 2 flooding; c: area 3 flooding; d: area 4 flooding; e: water level profile of node TQ-J18-TQ-J16 in area 3).

In the part of area 1 that was flooded, node TQ-J1 was located at the end of a pipe which collected flow from many surrounding pipes. The catchment area is large, causing large flow in the node. Such a heavy flow of rainwater can only be drained 
through pipe TQ-L2, which is lower than the surrounding terrain. The flooding around this node was serious. In order to reduce the flooding, the drainage capacity of the flooded area should be increased. Thus, to cater for the increased drainage demand, another pump model ZBL2.8-6.7 will be installed.

The SWMM status report showed that in the part of area 2 that was flooded the flooding was not that serious. Water at node TQ-J6 downstream of the main pipe started flowing back to node TQ-J9. When the pipeline between nodes TQ-J10 and TQ-J11 was full, the drainage capacity was limited. However, installing the pump in area 1 improved the situation, so there was no need to reconstruct the network in area 2.

In the flooded part of area 3, shown in Figure 7e, the terrain around node TQ-J17 was low, and the pipe downstream had an adverse slope, making it difficult to drain. This is why there were $2.06 \mathrm{~h}$ of flood for the node and the total flood volume rose to $15.762 \mathrm{~m}^{3}$. In addition, the diameter of the only drainage pipeline, TQ-L20, for node TQ-J17 was only $450 \mathrm{~mm}$, which is another factor that contributed to the flooding problem in this area. The specific reconstruction actions were as follows. Another drainage pathway was created for node TQ-J17 by building the $1400 \mathrm{~mm}$ diameter pipeline TQ-L40 to link the node to node TQ-J21. The diameters of pipelines TQ-L21, TQ-L22 and TQ-L20 were all adjusted from $450 \mathrm{~mm}, 1000 \mathrm{~mm}$ and $1000 \mathrm{~mm}$ to $1200 \mathrm{~mm}$.

The flood inundation in area 4 was quite serious. According to the SWMM status report, the duration of flooding at nodes TQJ30, TQ-J31 and TQ-J32 was $1.11 \mathrm{~h}, 1.10 \mathrm{~h}$ and $1.14 \mathrm{~h}$. Node TQ-J32 is a start node with a large catchment area and the diameter of its downstream pipeline TQ-L37 was only $800 \mathrm{~mm}$, which increased the drainage problem and made it the most seriously flooded node. The main reason for the flooding at node TQ-J30 was that the diameter of its drainage pipeline TQ-L38 was only $600 \mathrm{~mm}$. The drainage network in this area could be improved by using larger diameter pipes. The diameters of pipelines TQ-L37, TQ-L36 and TQ-L38 were increased from $800 \mathrm{~mm}, 1000 \mathrm{~mm}$ and $600 \mathrm{~mm}$ to $1000 \mathrm{~mm}, 1200 \mathrm{~mm}$ and $800 \mathrm{~mm}$.

\subsection{Building Detention Tanks}

The area and depth of each detention tank were determined by the flood volumes of the nodes in surrounding areas. Because of the interactions of water flows in pipes, when the storage volume of the tank reached the maximum, the total flood volume of nearby nodes was partially stored in the tank and the flooding of the upstream nodes should should be limited to $\leq 1 \mathrm{~h}$ (MHURD 2014). The maximum water volume of a single detention tank can be corrected or adjusted based on the total flood volume.

TQ is in the PD New District, and the drainage systems are mainly separated. According to the code for the design of outdoor wastewater engineering, approved in 2016 (MHURD of China 2016), the effective volume of a rainwater detention tank for controlling runoff contamination of a separate system can be calculated according to Equation 2:

$$
V=10 D F \Psi \beta
$$

where:

$$
\begin{aligned}
V= & \text { effective volume of the detention tank, } \mathrm{m}^{3}, \\
D= & \text { water depth of the tank, } \mathrm{mm}(4 \mathrm{~mm}-8 \mathrm{~mm} \\
& \quad \text { calculated as rainfall depth }), \\
F= & \text { catchment area, ha, } \\
\psi= & \text { runoff coefficient, and } \\
\beta= & \text { safety factor, } 1.1-1.5 .
\end{aligned}
$$

A detention system consisting of several distributed smaller tanks has a greater effect on flood control than just one larger detention tank. Therefore we used the more efficient system of distributed tanks rather than the construction of one large detention tank near the outlet. The tanks were sited using the method described above, which takes account of factors such as the flooding situation, the surrounding buildings, terrain, elevation, and the cause of flooding.

Since area 1 is surrounded by residential and commercial buildings, and is close to a subway station, this area is not suitable for building a detention tank because of safety concerns. However, the flooding problems in this area could be eased by detention tanks elsewhere. In area 2, node TQ-J10 is close to a park and surrounded by green land, making it a safe place to build a detention tank. The green land area of the park is sufficiently large $\left(1500 \mathrm{~m}^{2}\right)$ so we modeled an underground cylindrical detention tank $20 \mathrm{~m}$ diameter and $4.78 \mathrm{~m}$ deep for this study. In area 3, node TQ-J22 is also close to a park and near a constructed wetland, so it is also an ideal place to build a detention tank. The construction was as follows. The green parkland area of TQ Park is $1500 \mathrm{~m}^{2}$ and according to engineering practice, an underground cylindrical detention tank with volume $2800 \mathrm{~m}^{3}, 24 \mathrm{~m}$ diameter and 6.19 m deep was built there. In area 4, LY primary school, LG nursery school and ZC hospital are near nodes TQ-J30, TQ-J31 and TQ-J32. To safeguard people and reduce risk, a detention tank should be built here. An underground cylindrical detention tank with volume $1890 \mathrm{~m}^{3}, 20$ m diameter and 6.05 m deep was constructed on the open space near LJZ Golden Sunshine Nursing Home.

\section{Results and Discussion}

The InfoWorks ICM simulation of the flooding areas, based on the waterlogged points chosen (Yin and Zhou 2009), is consistent with observation, so the model is practical.

\subsection{LID Rainfall Control Technology}

The main materials used in permeable pavement are water-permeable brick, sand, pervious concrete and macadam. The current market prices, used for calculating the costs of these materials, were $\$ 5.99 / \mathrm{m}^{2}, \$ 14.99 / \mathrm{t}, \$ 22.49 / \mathrm{m}^{2}$ and $\$ 10.49 / \mathrm{m}^{3}$ (Zhuoxi et al. 2012). The permeable pavement in area 1 is $1100 \mathrm{~m}$ long and $1.5 \mathrm{~m}$ wide, and the permeable pavement in area 3 is $930 \mathrm{~m}$ long and $1.5 \mathrm{~m}$ wide. The total cost of paving these two areas is $\sim \$ 0.187$ million, and the unit cost is $\sim \$ 92.2 / \mathrm{m}$ (including the 
permeable pavement on both sides of the road). The current market price of natural grass for sunken green spaces was $\$ 2.5 / \mathrm{m}^{2}-\$ 8 / \mathrm{m}^{2}$. At a cost of $\$ 0.60 / \mathrm{m}^{2}$, grassing this area would cost $\sim \$ 0.468$ million. The maximum costs of using LID practices to solve the problems of flooding in TQ community were $\$ 0.655$ million. The outcomes of implementing LID technologies are that the total flooding volume is reduced by $8.57 \%$ and the pipe flow rate decreases by $7.90 \%$. However, the sunken green space cannot be used as the only means of rainwater drainage; it must be combined with other methods to better solve the problems of urban rainwater and flood management (Qin et al. 2013).

\subsection{The Drainage Network Reconstruction by}

\section{Enhancing the Drainage Capacity}

The effects of the measures taken to increase the drainage capacity of the network for the four seriously flooded areas are shown in Table 2.

Table 2 Hours flooded at nodes before and after reconstruction.

\begin{tabular}{|c|c|c|c|c|}
\hline \multirow[b]{2}{*}{ Area } & \multirow[b]{2}{*}{ Reconstruction measures } & \multicolumn{3}{|c|}{ Hours flooded at node } \\
\hline & & $\begin{array}{c}\text { Seriously } \\
\text { flooded } \\
\text { node }\end{array}$ & $\begin{array}{l}\text { Before } \\
\text { reconstruction }\end{array}$ & $\begin{array}{c}\text { After } \\
\text { reconstruction }\end{array}$ \\
\hline Area 1 & Construct another ZBL2.8-6.7 pump. & TQ-J1 & 1.14 & 0.78 \\
\hline Area 2 & None. & TQ-J10 & 1.13 & 0.94 \\
\hline \multirow[t]{7}{*}{ Area 3} & Rebuilding pipe TQ-L40, with a diameter & TQ-J17 & 2.06 & 1.26 \\
\hline & of $1400 \mathrm{~mm}$, to link the node with node & TQ-J18 & 1.58 & 1.09 \\
\hline & TQ-J21. & TQ-J19 & 1.94 & 0.01 \\
\hline & The diameters of pipes TQ-L21, TQ-L22 & & & \\
\hline & and TQ-L20 were adjusted from 450 & & & \\
\hline & $\mathrm{mm}, 1000 \mathrm{~mm}$ and $1000 \mathrm{~mm}$ to 1200 & & & \\
\hline & $\mathrm{mm}$. & & & \\
\hline \multirow[t]{3}{*}{ Area 4} & The diameters of pipes TQ-L37, TQ-L36 & TQ-J30 & 1.11 & 1.09 \\
\hline & and TQ-L38 were increased from & TQ-J31 & 1.10 & 0.58 \\
\hline & $\begin{array}{l}800 \mathrm{~mm}, 1000 \mathrm{~mm} \text { and } 600 \mathrm{~mm} \text { to } \\
1000 \mathrm{~mm}, 1200 \mathrm{~mm} \text { and } 600 \mathrm{~mm} \text {. }\end{array}$ & TQ-J32 & 1.14 & 0.93 \\
\hline
\end{tabular}

After network reconstruction, the numbers of hours flooded at each node in the seriously flooded areas decreased, generally to $<1 \mathrm{~h}$, showing that drainage had been greatly improved. However, there were still some nodes with hours flooded $>1 \mathrm{~h}$. Drainage could be improved at these nodes by green municipal engineering rather than network reconstruction. Otherwise, the cost would be much higher and the loss will outweigh the gains.

The node flooding characteristics before and after network reconstruction are shown in Figure 8 . After reconstruction, most flooding at the nodes is $\leq 1 \mathrm{~h}$ and the total flood volume also decreases considerably, which shows that the network is basically able to fulfill the drainage demand for $20 \mathrm{y}$ storms.
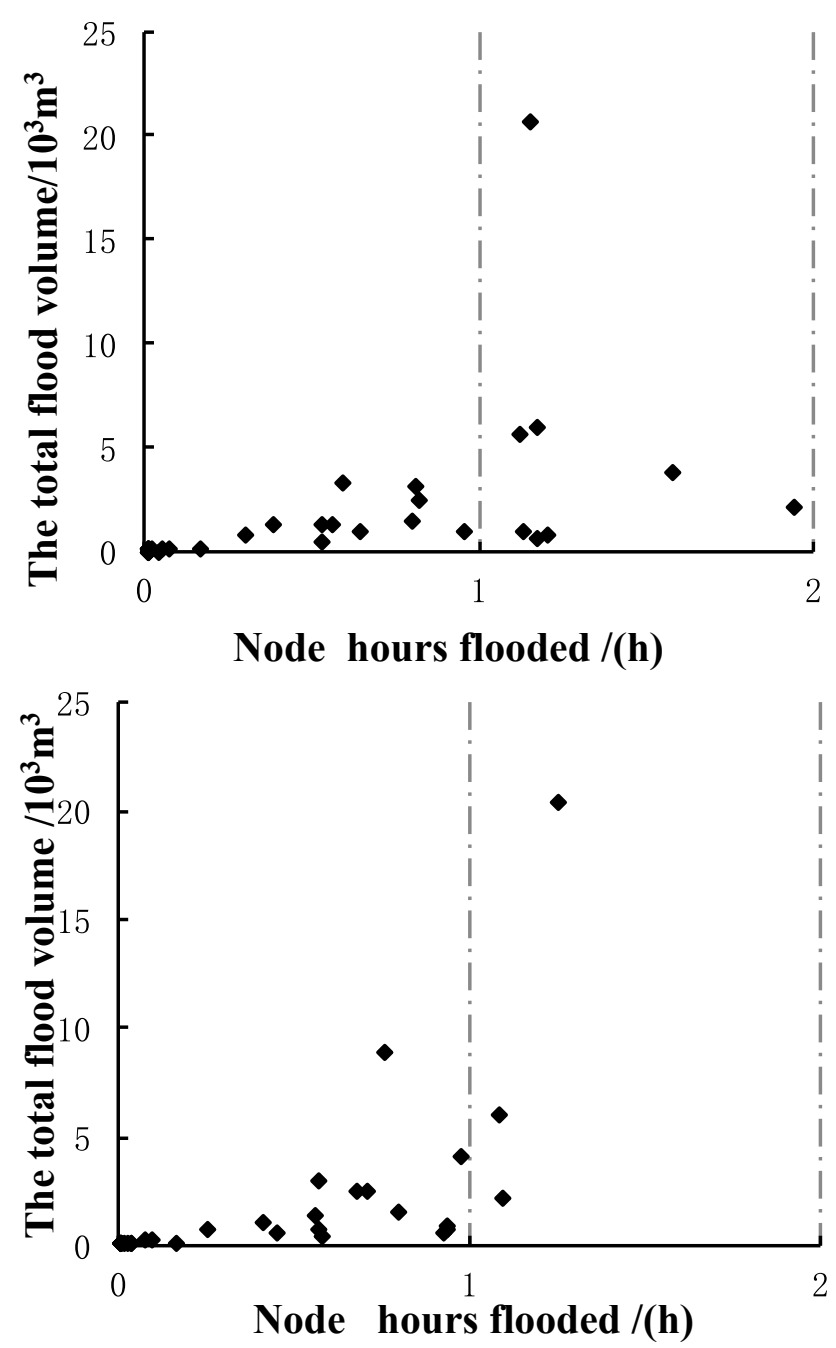

Figure 8 The node flooding characters before (upper)and after (lower) network reconstruction, with dashed lines indicating the $1 \mathrm{~h}$ threshold outline (Elliott and Trowsdale 2007).

According to Cao and Deng (1997), the total cost function of the drainage network reconstruction is, without regard for depreciation and management costs:

$$
C=\sum_{i=1}^{n}\left(C_{p m i}+C_{p s i}\right)+\sum_{i=1}^{n} \sum_{j=1}^{t i}\left(C_{w m i j}+C_{w h i j}+C_{w s i j}\right)
$$

where:

$$
\begin{aligned}
n & =\text { total number of pipes, } \\
t i & =\text { total number of inspection wells, } \\
C_{p m i} & =\text { cost of pipe material, } \\
C_{p s i} & =\text { cost of earthworks for pipeline, } \\
C_{w m i j} & =\text { cost of inspection well material, } \\
C_{w h i j} & =\text { labor cost for building the inspection wells, } \\
C_{w s i j} & =\text { cost of earthworks for inspection wells, } \\
j & =\text { \# of inspection wells, and } \\
i & =\text { \# of pipes. }
\end{aligned}
$$


The total cost of the drainage network reconstruction in TQ was $\$ 1.59$ million. The direct reconstruction work cost $\$ 1.47$ million, including $\$ 750000$ for the newly added pumps and their supporting facilities, $\$ 0.71$ million for the pipeline reconstruction, $\$ 120000$ for removing and transporting the original pipes, $\$ 0.23$ million for road repairs and $\$ 0.28$ million for other costs.

\subsection{Building Detention Tanks}

Figure 9 shows the node flooding characteristics before and after adding the detention tanks. Comparison of the figures shows that most of the floods at the nodes were $\leq 1 \mathrm{~h}$. However, the system still needs improvement because nodes TQ-J17 and TQ$\mathrm{J} 19$ were flooded for $>1 \mathrm{~h}$.
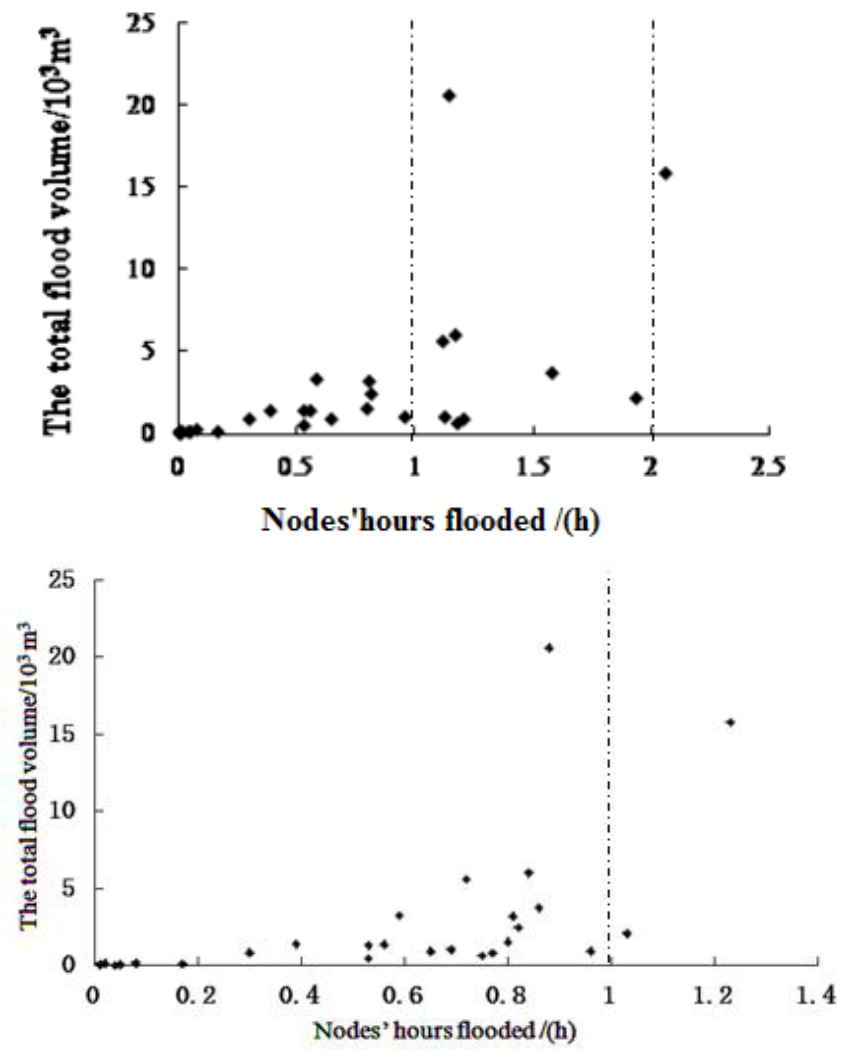

Figure 9 Node flooding characteristics with detention tanks before (upper) and after (lower).

According to the costs of earthworks and ground levelling given in the Estimated Index of Municipal Engineering in SH City, the costs of detention tanks in areas 2, 3 and 4 are $\$ 0.34$ million, $\$ 0.79$ million and $\$ 0.53$ million. The total cost is $\$ 1.74$ million and the average cost is $\$ 750 / \mathrm{m}^{3}$.

\subsection{Comparison of Results}

The results of the cost effectiveness analysis of the three technologies for alleviating urban flooding in TQ were compared. Table 3 shows the effects of the three construction methods and their costs. Each method will reduce flooding, but they all have limitations. Drainage network reconstruction and building detention tanks, for example, are both expensive. When comparing the effects of reducing the flooding duration (Figure 10) it can be seen that installing new detention tanks is more effective in reducing flooding.

Table 3 Dollars per hour of flooding technology in TQ.

\begin{tabular}{|c|c|c|c|}
\hline $\begin{array}{l}\text { Project } \\
\text { Items constructed }\end{array}$ & $\begin{array}{l}\text { LID technology } \\
\text { Permeable pavement }\end{array}$ & $\begin{array}{l}\text { LID with drainage } \\
\text { system reconstruction } \\
\text { Add pump }\end{array}$ & $\begin{array}{l}\text { LID with detention tank } \\
\text { construction } \\
\text { Add three detention }\end{array}$ \\
\hline & $\begin{array}{l}\text { Sunken green space } \\
\text { technology }\end{array}$ & $\begin{array}{l}\text { Adjust the diameters of } \\
\text { some pipes }\end{array}$ & tanks \\
\hline Construction cost & $\$ 0.34$ million & $\$ 1.59$ million & \$1.74 million \\
\hline Effects & $\begin{array}{l}\text { The flooding total } \\
\text { volume reduced by } \\
8.57 \% \\
\text { Peak pipe flow rate } \\
\text { decreased by } 7.90 \%\end{array}$ & $\begin{array}{l}\text { Flood volume decreased } \\
\text { by } 38.4 \% \\
\text { Peak flow decreased by } \\
58.9 \%\end{array}$ & $\begin{array}{l}\text { Flood volume decreased } \\
\text { by } 46.6 \% \\
\text { Peak flow decreased by } \\
50.1 \%\end{array}$ \\
\hline Limitations & $\begin{array}{l}\text { Can only be used as an } \\
\text { auxiliary measure }\end{array}$ & $\begin{array}{l}\text { Relatively high cost } \\
\text { Negative impacts } \\
\text { on the surrounding } \\
\text { environment under } \\
\text { construction } \\
\text { Other measures need to } \\
\text { be used }\end{array}$ & $\begin{array}{l}\text { Relatively high cost } \\
\text { Occupies a large area }\end{array}$ \\
\hline
\end{tabular}

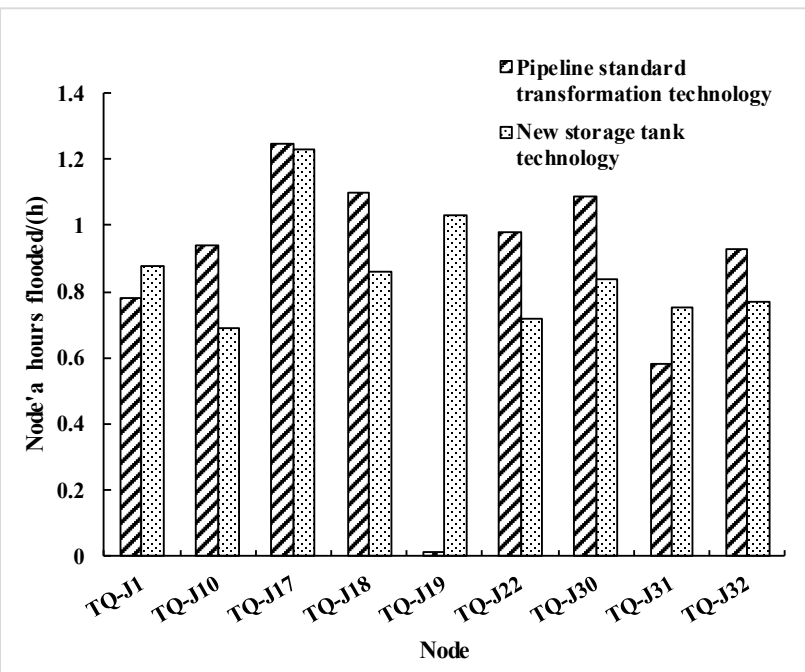

Figure 10 Effects of drainage network reconstruction and building detention tanks.

\section{Conclusions}

This paper discussed the modeling of LID practices, drainage network reconstruction and detention tank construction in catchments in TQ in SH city and analysed them in terms of construction costs and their effectiveness in reducing urban flooding.

Compared to grey or conventional construction, the use of LID practices is substantially influenced by land conditions and hydrologic characteristics such as the proportion of green areas, water coverage and the number of extreme rain events in a certain period. LID design alone cannot address the flooding problems without adequate water conveyance and storage capacity, especially in extreme rainstorms. Thus, in TQ, it is necessary 
to combine LID design with grey flood reduction infrastructure to mitigate the risk of urban flooding resulting from extreme rain events. Grey infrastructure, which we consider to be the same as conventional infrastructure, is simulated by drainage network reconstruction and detention tank construction. Modeling results show that detention tank construction is better for reducing total flood volume than drainage network reconstruction $(46.6 \%$ reduction versus $38.4 \%$ ). However, the peak flow reduction for detention construction it is $50.1 \%$ while for drainage network reconstruction it is $58.9 \%$.

Taking a closer look at the simulation, the modeling results show that 3 nodes have flooding times $>1 \mathrm{~h}$ even after drainage network reconstruction. Detention tanks are more effective, with only 2 nodes flooding for $>1 \mathrm{~h}$. Clearly detention tank construction provides greater flooding reduction than drainage network reconstruction. However, detention tank construction costs are $\$ 1.74$ million, higher than the network reconstruction costs of $\$ 1.59$ million.

Overall, this study shows an example of how to choose stormwater management solutions by comparing their construction costs and effectiveness in flood mitigation in the TQ area of SH city. As flood severity increases in the southeast of China, this work provides a general guideline and reference regarding how to select LID practices and how to determine which grey technique is more suitable to combine with LID practices for reducing flooding in other southeastern cities with high water coverage ratios.

This study has value for urban stormwater system design, planning, and construction. Future research may focus on analyzing the cost-effectiveness of multiple LID practices coupled with conventional infrastructure and consider operating and maintenance expenses and life cycle assessments.

\section{Acknowledgments}

We give great thanks to the PD Drainage Management Administration for their data support. We greatly appreciate the financial support from the Scientific Innovation and Development Fund of PD New Area of SH City.

\section{References}

Ahiablame, L. M., B. A. Engel and I. Chaubey. 2012. “Effectiveness of Low Impact Development Practices: Literature Review and Suggestions for Future Research." Water, Air, \& Soil Pollution 223 (7): 4253-73.

Andoh, R. Y. G. and C. Declerck. 1997. “A Cost Effective Approach to Stormwater Management? Source Control and Distributed Storage." Water Science and Technology 36 (8-9): 307-11.

Butler, D. and J. W. Davies. 2000. Urban Drainage. London: Spon.

Cao, A. G. and Deng, Z. Y. 1997. “Costs Equation Study for Urban Drainage System Construction. " Natural Journal of Xiangtan University, 19(1), pp.110-114.

Chen, S., B. Chen and B. D. Fath. 2014. “Urban Ecosystem Modeling and Global Change: Potential for Rational Urban Manage- ment and Emissions Mitigation." Environmental Pollution 190:139-49.

Chukwuma, G.O. and Schwab, G.O., 1983. Procedure for developing design hyetographs for small watersheds. Transactions of the ASAE, 26(5), pp.1386-1389.

Cizek, A. R., W. F. Hunt, R. J. Winston and M. S. Lauffer.2017. "Hydrologic Performance of Regenerative Stormwater Conveyance in the North Carolina Coastal Plain." Journal of Environmental Engineering 143 (9).

Damodaram, C., M. H. Giacomoni, C. Prakash Khedun, H. Holmes, A. Ryan, W. Saour and E. M. Zechman. 2010. "Simulation of Combined Best Management Practices and Low Impact Development for Sustainable Stormwater Management 1." JAWRA Journal of the American Water Resources Association 46 (5): 907-18.

Damodaram, C. and E. M. Zechman. 2012. "Simulation-Optimization Approach to Design Low Impact Development for Managing Peak Flow Alterations in Urbanizing Watersheds." Journal of Water Resources Planning and Management 139 (3): 290-8.

Elliott, A. H. and S. A. Trowsdale. 2007. "A Review of Models for Low Impact Urban Stormwater Drainage." Environmental Modeling \& Software 22 (3): 394-405.

Gilroy, K. L. and R. H. McCuen 2012. "A Nonstationary Flood Frequency Analysis Method to Adjust for Future Climate Change and Urbanization." Journal of Hydrology 414:40-8.

Gironás, J., L. A. Roesner, J. Davis, L. A. Rossman and W. Supply. 2009. Storm Water Management Model Applications Manual. Cincinnati, OH: U.S. Environmental Protection Agency National Risk Management Research Laboratory, Office of Research and Development.

Hammond, M. J., A. S. Chen, S. Djordjević, D. Butler and O. Mark. 2015. “Urban Flood Impact Assessment: A State-of-the-Art Review." Urban Water Journal 12 (1): 14-29.

Hu, M., T. Sayama, X. Zhang, K. Tanaka, K. Takara and H. Yang 2017. "Evaluation of Low Impact Development Approach for Mitigating Flood Inundation at a Watershed Scale in China." Journal of Environmental Management 193:430-8.

Hu, Z. F., Z. Q. Yue, J. Zhou and L. G. Tham. 2003. “Design and Construction of a Deep Excavation in Soft Soils Adjacent to the SH City Metro Tunnels." Canadian Geotechnical Journal 40 (5): 933-48.

IPCC. 2014. Climate Change 2014: Impacts, Adaptation, and Vulnerability. Cambridge: Cambridge University Press.

Liu, W., W. Chen and C. Peng. 2014. "Assessing the Effectiveness of Green Infrastructures on Urban Flooding Reduction: A Community Scale Study." Ecological Modeling 291:6-14.

Liu, Y., L. M. Ahiablame, V. F. Bralts and B. A. Engel. 2015. “Enhancing a Rainfall-Runoff Model to Assess the Impacts of BMPs and LID Practices on Storm Runoff." Journal of Environmental Management 147:12-23.

Liu, Y., R. Cibin, V. F. Bralts, I. Chaubey, L. C. Bowling and B. A. Engel. 
2016. “Optimal Selection and Placement of BMPs and LID Practices with a Rainfall-Runoff Model." Environmental Modeling \& Software 80:281-296.

Ministry of Housing and Urban Rural Development of the People's Republic of China (MHURD). 2016. Code for Design of Outdoor Wastewater Engineering [S]. (In Chinese.)

Palhegyi, G. E. 2009. “Designing Storm-Water Controls to Promote Sustainable Ecosystems: Science and Application." Journal of Hydrologic Engineering 15 (6): 504-11.

Pan, C. L., and Chiu, H. S. 2000. Research Project Report for Evaluation of Using No-Fines Concrete and Permeable Walkway Construction Techniques. Architecture \& Building Research Institute, Ministry of Interior. (In Chinese.)

Qin, H. P., Z. X. Li and G. Fu. 2013. "The Effects of Low Impact Development on Urban Flooding under Different Rainfall Characteristics." Journal of Environmental Management 129:577-85.

Quan, R. S., M. Liu, M. Lu, L. J. Zhang, J. J. Wang and S. Y. Xu. 2010. "Waterlogging Risk Assessment Based on Land Use/Cover Change: A Case Study in Pudong New Area, SH City." Environmental Earth Sciences 61 (6): 1113-21.

Rhodes, G. and F. Fice. 2014. "Realising the Benefits of Integrated Urban Drainage Models." Proceedings of the Institution of Civil Engineers 167 (1): 30.

Rossman, L. A. 2010. Storm Water Management Model User's Manual, Version 5.0. Cincinnati, OH: U.S. Environmental Protection Agency National Risk Management Research Laboratory, Office of Research and Development.

Schneider, L. E. and R. H. McCuen. 2006. "Assessing the Hydrologic Performance of Best Management Practices." Journal of Hydrologic Engineering 11 (3): 278-81.
Sun, Y., C. A. Pomeroy, S. Lü and C. Xu. 2016. “Hydrological Regulation Performances of LID Practices Based on Different Rainfall Reappearance Periods." Nongye Jixie Xuebao/Transactions of the Chinese Society of Agricultural Machinery 47 (6): 178-86.

UNISDR. 2015. 2015 Disasters in Numbers. Louvain: Université catholique de Louvain, Centre for Research on the Epidemiology of Disasters (CRED), IRSS.

https://www.unisdr.org/files/47804_2015disastertrendsinfographic.pdf.

Waters, D., W. E. Watt, J. Marsalek and B. C. Anderson. 2003. "Adaptation of a Storm Drainage System to Accommodate Increased Rainfall Resulting from Climate Change." Journal of Environmental Planning and Management 46 (5): 755-70.

Wei, Z. X., G. Y. Zhai and X. X. Yan. 2010. Atlas of Shanghai Urban Geology. Beijing: Geology Press. (In Chinese.)

Yin, Y. and J. E. Zhou. 2009. “Discussion of Relevant Issues of Tender Control Price under New Code of Valuation with Bill Quantity of Construction Works." Construction Economy 3:27.

Zhang, B., G. Xie, C. Zhang and J. Zhang. 2012. "The Economic Benefits of Rainwater-Runoff Reduction by Urban Green Spaces: A Case Study in Beijing, China." Journal of Environmental Management 100:65-71.

Zhuoxi, L. I., Q. I. N. Huapeng and X. I. E. Kun. 2012."Hydrological Effect Analysis of Low Impact Development under Different Rainfall Conditions." China Water \& Wastewater 28 (21): 37-41. 